\title{
The Best Course of Action
}

\author{
Louis P. D’Elia (Corresponding Author) \\ Dept. of Accounting and Business Law, Saint Francis College \\ 180 Remsen Street, Brooklyn, N.Y. 11201 \\ Tel: 1-718-489-5288Ｅ-mail: 1delia@sfc.edu
}

Richard Gunter
Department of Business, University of Saint Mary
4100 South $4^{\text {th }}$ Street, Leavenworth, KS 66048
Tel: $1-913-758-4338 \quad$ E-mail: richard.gunter@stmary.edu

Timothy R. Wiseman

Tapia College of Business, Saint Leo University

33701 State Rd 52, St. Leo, FL 33574

Tel: 1-352-588-7386 E-mail: timothy.wiseman@saintleo.edu

Received: June 10, 2019 Accepted: June 22, 2019 Published: June 24, 2019

doi:10.5296/csbm.v6i1.14942 URL: http://dx.doi.org/10.5296/csbm.v6i1.14942

\begin{abstract}
This case describes the ethical and legal challenges facing Dr. Caroline Webster, Director of Graduate Business Programs at MNU. She was facing one of the more unpleasant tasks of her job in determining how to proceed with a complaint by one of the university's Master's students by the name of Bob Golden. Although a solid and intelligent student in his own right, Bob continuously challenged his grades, causing some faculty and administration to grow weary of his seemingly constant complaints. Dr. Webster wistfully recalled no less than a dozen unrelated prior instances. However, this current complaint was beyond Bob's normal grievance. During a conversation with Dr. Webster, Bob claimed that the instructor for his current course, Adjunct Professor Joe Thomas, had a criminal past. After a quick and rather basic search, it turned out that Professor Thomas had indeed been convicted of a felony approximately a decade and a half earlier. Naturally, Dr. Webster took the matter up to Dr.
\end{abstract}




\section{Macrothink}

Donald Hess, Dean of the MNU Business School, who was now faced with the decision of whether or not he needed to terminate the employment of Adjunct Professor Joseph Thomas. Collectively and apart from the grading complaint, they also had to decide on the proper course of action as a follow-up to Bob Golden's allegation. The class which Adjunct Professor Thomas taught was the final and capstone class of the MBA program at MNU. Ironically, the class was one with a considerable focus on ethics and morals in business.

Keywords: Criminal history, background checks, privacy, second-chance, core values 


\section{Introduction}

It was a beautiful, late fall day as Dr. Caroline Webster stared out her office window on the campus of Marvin Newman University. The leaves had long since passed from the bright reds, orange, and yellows of fall that made the campus of MNU so beautiful. There were just a few trees with leaves left on them now. Dr. Webster was lamenting the coming of winter. Still, it had been an unusually warm fall in the Midwest, and the campus continued to radiate with natural beauty. With a sigh, she turned away from the window and started toward the coffee pot for her second cup of the morning when the phone on her desk rang. She thought to let it go to voicemail, but decided to pick it up. It was a decision she would come to regret.

Dr. Webster picked up the phone and heard the voice of Nathan Green on the other end of the line. "Dr. Webster?" said Nathan, his voice filled with both worry and disgust. Nathan Green was one of the advisors in the MBA program at MNU. Nathan, an extremely capable assistant, could usually handle any issue long before it reached Dr. Webster's desk. "I heard from Bob Golden," Nathan said. He took a deep breath and sighed. "He's complaining about his instructor in the capstone class."

\section{Background - Dr. Caroline Webster}

Dr. Webster started out in the corporate world after graduating with a Bachelor's degree in business. After a brief period of time at a mid-level management position with a large company, she decided to return to school and pursue a Master's degree in business from a small local university. Upon earning her MBA, Caroline Webster began teaching part-time as an adjunct professor. She was hooked. From the moment she stepped into the classroom, she knew this is what she wanted to do. She found a part-time doctoral program in business and after several years and a good deal of hard work, graduated with a Ph.D. in business. Through one of her classmates, the now Dr. Caroline Webster was hired as an Associate Professor of Business at Marvin Newman University.

Marvin Newman University (MNU) is a small Midwestern liberal arts university with approximately 1,500 students. The Business program at MNU, although relatively small, is one of the university's most popular programs. In addition to the traditional on-campus undergraduate program, MNU offers an MBA with classes at night for working adults. As is the trend with many higher educational institutions, several years ago MNU created an online MBA program. Caroline Webster had been instrumental in getting the online MBA program off the ground. It was growing and gaining a good reputation. With the success of the MBA program, Caroline's stock with MNU was rising too.

It was at this time that the university opened a position for a Director of Graduate Business Programs. MNU posted the position on its website as well as a number of additional employment websites used by institutions of higher learning. Applications poured in and a committee was formed. As part of the hiring process, applicants were exhaustively screened. Once cleared, several rounds of interviews were performed before selecting the new director. At the last faculty meeting of the academic year, the Provost announced that Dr. Caroline Webster was chosen as the new Director of the MBA Program at MNU. 


\section{Background - Adjunct Professor Joseph Thomas}

He loved working - in any capacity - and proudly considered himself a workaholic. By any measure, Joe Thomas' background was an impressive one that displayed success spanning more than two decades. As a practicing attorney, entrepreneur, business partner, consultant, mentor, and adjunct professor, Joe seemed to possess the perfect combination of the real world and academic experience. The self-described "workaholic" seemed to find his panacea in the classroom. As a result, Joe had looked to take on additional teaching assignments. Two years prior, Joe had been perusing a number of ads from various American colleges and universities seeking qualified adjunct professors. When he came across the MNU ad looking for an adjunct professor to teach the capstone Strategic Management and Ethics class in its highly successful online MBA program, Joe excitedly applied for the position. He knew it would be a great opportunity for him to teach a class that provided much needed time flexibility in his hectic work schedule. He had also silently hoped that it could lead to an even bigger role in the online program.

In response to the ad for the position as an adjunct professor, Joe was asked to submit a cover letter, most recent resume (curriculum vitae), transcripts, and three professional references. After receiving and reviewing the required material, the Human Resource Department of MNU forwarded a copy of the resume and references to Dr. Webster as well as the Dean of the Business School, Dr. Donald Hess. With his impressive educational, professional, and teaching background, MNU decided to contact Joe to set up an interview. Since Joe lived a few thousand miles away in the South, the interview was conducted via Skype. Attending the interview were Dr. Carolyn Webster as well as Dr. Hess. After brief introductions and discourse regarding the requirements of the new position, a verbal offer was extended to and mutually agreed upon by the two parties.

It seemed to be such a natural fit. MNU was excited to be able to secure the services of such an impressive candidate without having to overextend its budget with the hiring of a full-time professor. As an adjunct, Joe would be treated as an "at-will" contract employee with no benefits or any other costs associated with full-time employment. All adjunct professors were required to sign a contract to teach one course at a time, with no guarantee the contract renewal. The adjunct contract stipulated that renewal was up to the sole discretion of the university and was dependent upon need and sufficient enrollment.

It seemed perfect for Joe as well as he had taught similar classes and simply needed to adapt his former lesson plans and syllabus to the curriculum at MNU.

As a new adjunct professor, the university sent Joe Thomas a hiring package that included a personal information form, federal and state tax withholding forms, an I-9 (proof of citizenship) form, and a contract to teach Strategic Management and Ethics for the upcoming term. Although surveys showed that a majority of employers - a whopping $92 \%$ according to one survey - obtained criminal background checks when hiring for some or all positions (Law on Employer Use, 2016), MNU did not require background checks on adjunct professors. As part of the hiring paperwork, adjunct professors were required to sign a statement that they had read and understood the Employee Handbook. However, there was no mention in the MNU Employee Handbook of any requirement to disclose criminal activity on the part of the 
employee prior to being hired by the university. Additionally, no reference to criminal history or background was made on the university website.

Dr. Webster, in conjunction with the provost and university board, had always emphasized the core values of "ethics and corporate responsibility" as espoused in the MNU mission statement. As it related to hiring practices, state law explicitly allowed employers to require applicants or candidates for independent contractor work to sign a release allowing the employer to access criminal records to determine fitness for employment. State law also specifically exempted employers from liability for decisions made on the basis of an applicant's or independent contractor's criminal record, as long as the information leading to the decision "reasonably bears" on the applicant's trustworthiness or the safety or well-being of the employer's employees or customers (Reference Intentionally Omitted). However, as part of their recruitment and hiring practices, MNU had been sensitive to the State Human Rights Commission that stated that it was "inadvisable" for employers to ask applicants anything about arrests, including the number and type of arrests, or to ask any questions about convictions unless they were "substantially related" to the applicant's ability to perform the job.

State law also provided that applicants need not disclose expunged records on an employment application. Still further, as a matter of best practices, MNU has taken the lead from Federal Title VII of the Civil Rights Act of 1964. This law sought to protect applicants and employees from discrimination in every aspect of employment, including screening practices and hiring. Because arrest and incarceration rates were so much higher for minority populations, an employer that adopted a blanket policy of excluding all applicants with a criminal record could be accused of discrimination on the basis of race discrimination (Law on Employer Use, 2016).

In summary, state law allowed employers to consider criminal records in hiring but cautioned employers against using arrest records or convictions that bore no relationship to the job (Reference Intentionally Omitted).

\section{MBA Candidate Robert Golden}

Bob Golden, a student in the online MBA program at MNU, had proven himself to be a high achiever. From the onset of his matriculation in the MBA program, however, Bob had found fault with both teacher and subject matter in a number of his courses. He consistently challenged the rules and deadlines as detailed in each course outline, questioned the fairness and decision-making ability of faculty, and challenged his grades throughout his entire two-year "stay" at MNU. Bob's complaints had become so commonplace that faculty and administration alike had been looking forward to his graduation day as an end to what had become a virtual routine of complaints and challenges. Most recently, Bob had been enrolled in MNU's capstone class entitled, "Strategic Management and Ethics." The online class had been assigned to and was being taught by Joseph Thomas, MBA, JD.

About halfway through the eight-week term, Bob, who had been consistently late on projects and subsequently penalized by Joe Thomas as outlined in the course syllabus, took umbrage with the penalties and grading. Bob had charged that Professor Thomas had been unfair in penalizing Bob's tardiness, but failed to provide any facts or other extenuating circumstances 
on which to lodge his complaint. With Professor Thomas holding the line, Bob sought the help and direction of Dr. Caroline Webster. After many back and forth conversations with student Bob Golden as well as Professor Joseph Thomas, Dr. Webster was able to convince Professor Thomas to extend the due date of the most recent paper by an additional and generous three weeks. Dr. Webster's motives included keeping the peace as well as fast-tracking the graduation and simultaneous freedom associated with Bob's finishing his program of study at MNU.

Against Professor Thomas' better judgment, but in the interest of avoiding any formal grievance, he acquiesced. Then, to his chagrin but not a surprise, Bob missed the extended deadline. At this point, Joe dug a line in the sand and indicated that it "wouldn't be fair" to the other MBA students in his class if he didn't penalize Bob for such wanton and habitual lateness. Despite late penalties on a number of assignments, Bob Golden earned a " $C$ " in the course and met all of the requirements to graduate with his MBA. Not satisfied with his grade and pending graduation status, Bob, once again, reached out to Dr. Webster to complain about the utter "unfairness" that Adjunct Professor Thomas had displayed in his refusal to understand the circumstances surrounding Bob's tardiness. Left with no real choice, the program director indicated that the professor and MNU administration had been more than fair and that Bob would have to live with the consequences of his actions.

\section{Golden's Steadfast Refusal to Accept the Decision of MNU}

Despite the best efforts of administration and faculty in extending numerous courtesies, Bob would not accept the inevitable decision. Unbeknownst to both Dr. Webster and Dean Hess, Bob continued his fight by contacting MNU's Provost, Dr. Robert Santos. In this episode, Bob had some new information and ammunition in his continuous quest to disparage Professor Thomas. During the conversation, Bob queried Provost Santos by smugly asking, "Do you know that you have a convicted felon teaching your Ethics class?" Provost Santos wasn't sure what Bob was getting at and asked for further clarification. In a typically mocking and didactic tone, Bob mentioned that a simple Google check of Dr. Thomas' background turned up a criminal history. Provost Santos graciously listened to Bob and then finished the phone call by offering him some consolation. As part of a formal grade appeal, Provost Santos made the unilateral decision to remove any late submission penalties and promised to have Bob's three most recent papers reviewed and graded by other "independent" professors at the university. While the university's grade-appeal policy did acknowledge the Provost as the ultimate decision-maker, the decision to override a professor's grades after a review by independent professors seemed counter to the spirit and fairness of the appeal process.

As Provost Santos hung up the phone, he shook his head vigorously and knew that he had to follow up on the salacious claim made by the student. He also pondered in silence about the ethics of a student prying into a teacher's background and wondered if the administration's placation of Bob fostered an environment that ultimately enabled and encouraged this type of nefarious behavior. He summoned both Dr. Webster and Dean Hess to share what had just transpired. Dr. Webster went right for her Smartphone. Sure enough, a quick and simple search found the accusations leveled by Bob to be true. Ironically, Joe Thomas had been convicted of a felonious theft that led to the loss of his law license and the ability to practice law. The 
realization and irony that the university had in its midst a felonious professor chosen to teach its Capstone Ethics class caused a quiet panic among the school's administrators.

A wave of concern and panic caused by the potential embarrassment and fallout of this "ethics" teacher being exposed as a felon was felt by the Provost, Business School Dean, and Dr. Webster alike. After a few moments of sheer dread, cooler heads prevailed. Dr. Webster began to do some research. While she could not locate any direct cases within the state, she found a plethora of articles and cases where a current professor's past criminal history surfaced after being hired.

What was the university to do? Should it give in to a student who was served exclusively by his own selfish interests? What about the potential liability of having a convicted felon as part of its teaching establishment? Had they unwittingly put any students in danger? What legal responsibilities, if any, did the university have to inform Joe Thomas of the findings, as well as the other schools where Joe Thomas taught - especially those where he taught ground classes?

On the opposite end of the spectrum, both the provost and director believed in second chances. Should a "one-time" conviction for a "white collar" crime devoid of any violence or other threat be enough to mar Joe Thomas' chance at work for the rest of his life? After all, he had paid his dues and restitution. Along those lines, was there an appropriate amount of time in which his record, and reputation, can be expunged of his felonious conviction?

\section{Final Outcomes and Decisions Rendered}

Professor Thomas had shown himself to be a good teacher with high expectations, whose grading was really thorough. The review of Bob Golden's last three assignments in the capstone course by the other independent professors in the university revealed that Bob did indeed earn a "C" in the course. The work was average at best and on one assignment, the independent professors actually gave Golden a lower score than did Professor Thomas. This information was given to the Dean of the Business School, Dr. Hess. Shortly thereafter, Dr. Hess sent an email to Bob Golden stating that the university had reviewed his assignments for the Capstone course and was satisfied that the grade was valid. MNU was considering the case closed and no further action on the grade would be taken. Dr. Hess closed the email with a statement congratulating Bob Golden on his graduation from the MBA program. In no great surprise, Bob Golden vowed to pursue additional legal recourse.

\section{What to Do with Professor Thomas?}

Despite the emotional and sympathetic pull to give Professor Thomas a second chance, the Provost and Director realized that the removal of Joe Thomas for future teaching assignments was in the university's best interest. The liability and potentially devastating public relations nightmare could be a crushing blow to a university and program founded on principles and ethical responsibilities. From a liability perspective, as a non-union adjunct faculty member with little to no rights, the non-renewal of the contract was left to the sole discretion of the administration and Dean of the Business School at MNU.

It was clearly the easiest and best course of action. Or was it? 


\section{Instructor's Manual}

\section{Dr. Thomas and Student Golden - Teaching Note}

\section{OBJECTIVES OF THE CASE}

There are a number of salient teaching and learning opportunities presented in this case study. For this teaching note, we have turned our attention to two primary areas of focus with reference to two less obvious ones. The first relates to the decision to accommodate the student at different points throughout the semester, specifically as the complaints bypassed standard protocol. The other relates to Professor Thomas and whether or not he should have been given a second chance. The third was whether or not the university had a legal, or ethical, obligation to inform Professor Thomas of its findings. Finally, did the university have an ethical responsibility to contact the other schools where Joe Thomas had been teaching?

We see the usefulness of the case in an online or face-to-face classroom discussion. To that end, students can be asked to role-play, with the non-participating students commenting on the ethical decisions made by the actors/actresses. Finally, the case study can be used to test a student's recognition of the ethical and legal challenges facing MNU.

\subsection{Courses and Levels}

We have discussed using this case at both the undergraduate and graduate levels as part of Organizational Behavior and Ethics and Corporate Responsibility classes. The case can also be used in undergraduate and graduate level ethics classes as well as business management classes whereby the student would be presented with the difficult decision of removing an otherwise model teacher. Finally, the legal issues raised helped make this case useful for Business Law students as well as first and second-year law students.

\subsection{Prerequisites: None}

\subsection{Case Synopsis}

The case describes the dilemma faced by MNU administration in addressing the specific complaints of Bob Golden, a matriculating MBA student in the online program at MNU. Bob, recognized for his persistent complaints and demands for exceptions and leniency throughout his matriculation at MNU, has once again found fault in an instructor's clearly documented grading rules. Not willing to accept responsibility for his own shortcomings, Bob brought his complaints about Dr. Thomas all the way up to the Provost. However, this time, Bob came carrying some new, and potentially problematic, information. As it turned out, Bob had "discovered" that Dr. Thomas had pleaded guilty to a felony many years ago. Therefore, MNU had to decide not only what to do about Bob's new grading complaint, but on the appropriate course of action as it related to Dr. Joseph Thomas as well.

\subsection{Key Issues}

The case lends itself to an analysis and discussion in a variety of different topics and subject areas. Two of the primary issues and questions we believe the case raises relate to ethical and legal issues. As highlighted above, we see the usefulness in an analysis by business majors studying Organizational Management, Ethics, Corporate Responsibility, Business Law, as well as seminal topics for first and second-year law students. The various legal issues inherent in the 
case include federal and state employment law, discrimination policy under TEFRA, civil rights, Freedom of Information Act compliance, privacy rights, Rehabilitation of Offenders Act of 1974, and contract law as it relates to adjunct faculty members.

A criminal record has become an impediment to employment in cities and states across the country. As a result, there are a number of laws and proposed laws that would prohibit a government employer from inquiring about the criminal background activity of prospective employees. There is increasing debate as to whether or not these laws should apply to private employers as well.

\subsection{Discussion Items and Questions}

a. Whether or not it is necessary to change the vetting procedure when hiring adjunct faculty to include some kind of formal background check.

b. With the advent and proliferation of the internet, and the plethora of information available online through a simple Google or Yahoo search, should a formal policy be implemented that allows, and perhaps inadvertently fosters an environment where students are encouraged to research the personal, business and criminal histories of their professors?

c. Does the benefit of cost reduction in hiring adjuncts (whose workload entitles them to no fringe benefits) outweigh the risks to the student population who essentially and potentially become captive prey to felonious instructors?

d. Should the university embark upon a "second chance" policy for faculty and administration alike? Would this require a definition of allowable offenses, or perhaps refer to some appropriate crime-free period of time in which said prospect could not be hired? If so, would there be a certain mandate as to how long a period must elapse to be considered a viable teaching candidate? Should there be some form of remediation process for non-violent offenders?

e. Would a simple questionnaire regarding criminal backgrounds of prospective adjuncts be sufficient (and legal) in removing said adjunct if undisclosed criminal activity comes to the attention of the administration?

f. Under the current scenario, what actions, if any, are appropriate by the ruling bodies at the university since there was no request to disclose the criminal history of the applicant?

g. Should the type, nature, and frequency of conviction factor into determining whether or not convicted felons will be given a second chance?

h. Should the university adopt a uniform policy that would require prospective faculty to come forth with convictions?

i. What type of background check, if any, should be administered to prospective employees? 


\section{Suggested Responses - Employment Of Dr. Thomas}

\subsection{Fire or Retain}

We believe that the discussion responses will vary from recommendations for immediate dismissal of the professor due to the lack of truthfulness to providing him with a second chance. A decision to terminate will invariably lead to opposing reactions whereby many students may see the professor as having no real choice in revealing his previous history as a felon.

\subsection{Inform or Remain Silent}

Discussion as to Professor Thomas' right to know should be a topic of consideration as it relates to privacy rights and human rights.

\subsection{Time Served or Unforgiveable Act}

Expectations that a certain portion of the students will believe that proper restitution was paid and that Professor Thomas was fully rehabilitated over the last fifteen odd years. Others will insist that felonious activity should be punished in-kind and that no period of time will be sufficient as a "cooling off" period.

\subsection{A Felony Is a Felony Vs. Consideration For Non-Violent Offenses}

Obviously, a felony is a serious conviction. However, Professor Thomas's conviction was 'white collar' in nature, with no hint of violence, threats or other egregious physical and or emotional intimidation. As a result, the debate as to the severity of the crime will invariably occur amongst students.

\section{Suggested Responses - Bob Golden}

\subsection{Extend Courtesy Versus Encourage Rule-Breaking}

Students should debate whether or not the courtesy extended by MNU was appropriate, extraordinary, or completely inappropriate as it relates to fairness. As life happens, was it an act of kindness and devotion to a student experiencing personal time constraints or did the administration foster an environment for making exceptions and giving in to what may be viewed as a student's unreasonable demands?

\subsection{A Stand-Up Man or A Spoiled Student That Overstepped Reasonable Boundaries}

Bob Golden will be seen by some as a maverick and one who had been courageous enough to question authority and unfairness. Others will argue that, given his past history and habitual lateness, this student should not have been afforded the extended courtesies due to a history of complaints and the inability to follow rules of order.

\section{Suggested Responses - MNU Responsibility}

\subsection{Accommodating or Emasculating Administrators}

Although not specifically outlined in the case, the expectation exists that certain students will debate MNU's role in the dilemmas created by the case study. As it relates to Bob Golden, did the school accommodate the student as a way of avoiding additional conflicts? On the other 


\section{Macrothink}

hand, were the efforts considered a means to an end (i.e. as an accelerator to graduate the student and remove a persistent thorn in the side of faculty and administration alike)? In their effort to appease the student, they chose to overturn Dr. Thomas' firm commitment to the course rules.

\subsection{Equal Opportunity Employer or Institution That Puts Students in Harms' Way}

A debate on MNU's responsibility in performing no-cost criminal background checks before hiring vs. the responsibility of applicants to voluntarily disclose past criminal history will ensue. Full-time applicants must answer a simple question regarding felonious convictions. Why did the university forego such an obvious safeguard in hiring Dr. Thomas? The fact that Dr. Thomas was hired to teach an online class with no face-to-face student ground interaction might be a mitigating factor that students will recognize. Still, students will invariably revisit the need and appropriateness for second chances, as well as the severity, nature, and timing of the criminal act. The irony of Dr. Thomas teaching a Capstone Ethics class should also be a topic of discussion.

\section{Review of Recent Cases}

Instructors may wish to add the following cases relating to professors who have been removed from service after the discovery of a criminal background.

Penn State University

Should Prospective Faculty Disclose Criminal Backgrounds? A Penn faculty committee votes against requiring information of all applicants, but some experts say that the questions should be asked of everyone, by Elia Powers. https://www.insidehighered.com/news/2008/03/07/criminal.

University of Illinois

In perhaps the most polarizing case, we found a legally questionable conviction related to a professor at the University of Illinois.

Professor with a Past, by Colleen Flaherty.

https://www.insidehighered.com/news/2014/05/08/contract-renewal-adjunct-criminal-past-rai ses-academic-freedom-concerns-illinois.

\section{Disguised Characters and Circumstances}

In light of the sensitivity and potentially harmful consequences of revealing the true characters involved in the case study below, the names of the characters and university have been changed. The ages, educational background, and work experience of the characters were all based upon real events and circumstances. 


\section{Macrothink \\ Case Studies in Business and Management \\ ISSN 2333-3324 \\ 2019, Vol. 6, No. 1}

\section{References}

Law on employer use of arrest and conviction records (2016). Retrieved from http://www.nolo.com/legal-encyclopedia/massachusetts-law-employer-use-arrest-convictionrecords.html

\section{Additional Readings and Other Resources Used}

Anonymous State Bar Complaint Records, Retrieved through Google Search.

Flaherty, C. (2014, May 8). Professor with a past: Should a history that includes membership in the Symbionese liberation army and jail time disqualify one from keeping an adjunct job? Even if the instructor was open about it and received rave teaching reviews? Retrieved February from

https://www.insidehighered.com/news/2014/05/08/contract-renewal-adjunct-criminal-past-rai ses-academic-freedom-concerns-illinois.

Linked - In, Public Background Information.

Lundberg, C. C., Rainsford, P., Shay, J.P., \& Young, C.A. (2001). Case writing reconsidered. Journal of Management Education, 25 (4), 450-463.

Naumes, W. \& Naumes, M. (2011). The art and craft of case writing ( $3^{\text {rd }}$ ed.). Armonk, NY: M.E. Sharpe.

Powers, E. (2008, March 7). Should prospective faculty disclose criminal backgrounds? A Penn faculty committee votes against requiring information of all applicants, but some experts say that the questions should be asked of everyone. Retrieved from https://www.insidehighered.com/news/2008/03/07/criminal

References Intentionally Omitted - Due to the sensitivity of the case and lack of formal authority to publish actual names, university and state law, this reference indicates that a citation, although called for, is omitted.

State Employment Practices, Various State Handbooks Intentionally Obscured.

Vega, G. (2013). The case writing workbook: A self-guided workshop. Armonk, NY: M.E. Sharpe.

\section{Copyrights}

Copyright for this article is retained by the author(s), with first publication rights granted to the journal.

This is an open-access article distributed under the terms and conditions of the Creative Commons Attribution license (http://creativecommons.org/licenses/by/4.0/). 